\title{
Taxonomic entity of Saussurea taquetii (Asteraceae) compared with S. japonica and S. pulchella
}

\author{
Eun-Mi SUN, Seon A YUN', Seung-Chul KIM' and Hyoung-Tak IM+ ${ }^{*}$ \\ Researcher, Gardens and Collections Management Team3, Baekdudaegan National Arboretum, Bonghwa 36209, Korea \\ ${ }^{1}$ Department of Biological Sciences, Sungkyunkwan University, Suwon 16419, Korea \\ ${ }^{2}$ Department of Biology, Chonnam National University, Gwangju 61186, Korea \\ (Received 2 September 2020; Revised 25 October 2021; Accepted 4 November 2021)
}

\begin{abstract}
Saussurea taquetii reported from Jejudo Island is either treated as a synonym of S. japonica or is recognized as a distinct taxon. Saussurea japonica and $S$. pulchella belong to the sect. Theodorea by having peculiar outer phyllaries with pale purplish scarious apical appendages; they are closely related to each other morphologically and are known to occur widely throughout the Korean Peninsula. To assess the taxonomic status of $S$. taquetii, we investigated representative populations of $S$. taquetii from jejudo Island, Korea, and $S$. japonica from Kyushu in Japan. We conducted a comparative study morphologically using specimens of three species from KH, CNU, and TI. Saussurea taquetii is very similar morphologically and ecologically to S. japonica in Kyushu. Unlike previous floristic treatments, we concluded that the two taxa, S. pulchella and S. taquetii, occur on the Korean Peninsula and on jejudo Island, respectively.
\end{abstract}

Keywords: Saussurea japonica, Saussurea pulchella, Saussurea taquetii

해변취(Saussurea taquetii H. Lev. \& Vaniot)는 제주도에 서 채집된 Taquet의 표본(“Taquet, $10 \mathrm{Sep}$. 1908, Corea”)에 근거하여 취나물속(genus Saussurea)의 신종으로 보고되었 다(Léveillé, 1910). 해변취는 이년생 초본으로 지하경이 발 달하지 않고, 총포편의 선단에 옅은 보라색의 건막질 부속 체가 있어서 취나물속의 깃분취아절(sect. Theodorea)에 속 한다. 한반도의 sect. Theodorea에는 해변취 이외에 남포 분취(S. chinnampoensis H. Lev. \& Vaniot), 큰각시취 $(S$. japonica (Thunb.) DC.), 각시취(S. pulchella (Fisch.) Fisch.) 가 알려져 있다. 이 중 남포분취는 좁고 긴 피침형의 잎이 특징적이어서 큰각시취 및 각시취와 쉽게 구분되며, 북 한 서해안 지역과 중국 발해만 지역 해안에 국한되어 분 포한다. 각시취는 시베리아, 몽골, 중국 북부에서 일본까 지 분포하는 동북아 광역 분포종이다. 이에 비해 큰각시 취는 중국 중부, 타이완, 일본에 걸쳐 분포하는 종으로 각 시취의 분포와 넓게 겹치지만, 보다 저위도 지역에 분포 하는 종이다. 각시취와 큰각시취의 국내 분포에 대해서 는 대부분의 연구자가 전국의 산지 임연부 및 초지에 널 리 분포하는 것으로 인식하고 있다(Lipschitz, 1979; Koyama, 1995; Lee, 1998; Im, 1999; Lee, 2003; Shi and
Raab-Straube, 2011; Kadota, 2017) (Table 1).

해변취는 동북아 국화과 식물을 연구한 교토대학의 S. Kitamura에 의해 큰각시취의 이명으로 처리되었으며 (Kitamura, 1937), 취나물속의 monograph를 정리한 러시 아의 S. Lipschitz도 Kitamura의 견해에 따르고 있다 (Lipschitz, 1979). 그러나 조선식물지(Im, 1999)는 해변 취를 한반도 전역에 넓게 분포하는 각시취 및 큰각시취 와 다른 종으로 인식하고, 제주도 및 동해 연안의 섬에 분포한다고 기재하였다. 또한 국내에도 제주도의 해변 취는 본토의 큰각시취와 다르다고 주장하는 의견(사적 견해)이 상존하고 있다. 본 연구는 해변취, 큰각시취, 각 시취의 형태적 변이 폭과 분포 범위를 확인하여 해변취 의 분류학적 위치를 규명하기 위해 수행되었다.

\section{재료 및 방법}

해변취, 큰각시취, 각시취의 분포지와 형태적 변이 폭 을 확인하기 위해 국립수목원 $(\mathrm{KH})$, 전남대학교 생물학 과 표본실(CNU), 동경대학 표본관(TI)에 수장되어 있는 석엽표본을 조사하였다; 큰각시취 14점(일본 4점, 중국 6

\footnotetext{
*Author for correspondence: ihtplant@hanmail.net
} 
Table 1. Previous floristic treatments for Saussurea japonica, S. taquetii, and S. pulchella.

\begin{tabular}{|c|c|c|c|}
\hline Authors & S. japonica & S. taquetii & S. pulchella \\
\hline Lee (1998) & Central and north Korea & - & All parts of Korea \\
\hline Lee (2003) & All parts of Korea & - & All parts of Korea \\
\hline Lee (1996) & Nearly all parts of Korea & Syn. of S. japonica & All parts of Korea \\
\hline Korea National Arboretum (2016) & Central and north Korea & - & Central and north Korea \\
\hline Lipschitz (1979) & Korean peninsula & Syn. of S. japonica & Korean peninsula \\
\hline $\operatorname{Im}(1999)$ & All parts of Korea & Jeju and east coastal area & All parts of Korea \\
\hline Kadota (2017) & Korea & - & Korea \\
\hline Koyama (1995) & - & - & Korea \\
\hline Shi and Raab-Straube (2011) & Korea & Syn. of S. japonica & Korea \\
\hline
\end{tabular}

Table 2. List of plant materials and their geographical regions used in this study.

\begin{tabular}{|c|c|}
\hline Taxa & Collection site (herbarium) \\
\hline \multirow[t]{14}{*}{ Saussurea japonica } & Japan, Miyazaki Pref., Sonoki-gun, Togitsu-mura, 12 Oct. 1938, J. Chiba, 176 (TI) \\
\hline & Japan, Nagasaki Pref., Simabara-shi, Mt. Hikoyama, 30 Oct. 1972, T. Tominari (TI) \\
\hline & Japan, Kagoshima Pref. Kirishima shi, Mt. Kirishima, 1910, S. Yazima (TI) \\
\hline & Japan, Kumamoto Pref., Amakusa shi, Nt. Kadodake, 28 Oct. 1928, S. Saito (TI) \\
\hline & China, Shanxi Prov. Liuba county, Zibai Mountain Forest Park, 29 Aug. 2008, C. S. Chang et al., SX1623 (KH) \\
\hline & China, Liaoning Prov., Horodo, 5 Jul. 1931, S. Urata (TI) \\
\hline & China, Yunnan Prov., Danmu, 12 Oct. 1979, J. Murata et F. Yamazaki, 9287 (TI) \\
\hline & China, Jiangxi Prov., 13 Dec. 1941, F. Maekawa, 11 M158 (TI) \\
\hline & China, Sichuan Prov., Ruoergai Xian, 22 Aug. 2007, D. E. Buoffored et al., 40249 (TI) \\
\hline & China, Nei Mongol Prov., Xilin Gol Leagur, 6 Aug. 1993, D. E. Buoffored et al., 25906 (TI) \\
\hline & Taiwan, Hualien Hsien, near Panpien, 17 Aug. 1927, S. Saito, 7505 (TI) \\
\hline & Taiwan, Nantou Hsien, Wushe-Liying, 24 Aug. 1929, S. Saito, 242 (TI) \\
\hline & Taiwan, Gaoshung, between Gani and Bibyu, 29 Nov. 1938, M. Tagawa, 1217 (TI) \\
\hline & Taiwan, Taidung, 11 Dec. 1899, K. Miyake (TI) \\
\hline \multirow[t]{6}{*}{ Saussurea taquetii } & Korea, Jeju-do, “Quelpaert, Tchyung tchyeng,” 10 Sep. 1908, E. Taquet, 1015 (TI) \\
\hline & Korea, Jeju-do, Jeju-si, Yongduam, Aug. 1961, J. S. Lee, 1463 (KH) \\
\hline & Korea, Jeju-do, Jeju-si, Yongduam, 15 Aug. 2002, S. H. Park, 22618 (KH) \\
\hline & Korea, Jeju-do, Jeju-si, Yongduam, 7 Sep. 2005, H. T. Im, 057125 (CNU) \\
\hline & Korea, Jeju-do, Jeju-si, Dodubong, 18 Aug. 2017, H. T. Im, 173527 (CNU) \\
\hline & Korea, Jeju-do, Jeju-si, Byeoldobong, 15 Aug. 2017, H. T. Im, 173493 (CNU) \\
\hline \multirow[t]{6}{*}{ Saussurea pulchella } & Korea, Gangwon-do, Jeongseon-gun, Baekbok-ryeong, 8 Sep. 2010, H. T. Im, 122277 (KH) \\
\hline & Korea, Gangwon-do, Yeongwol-gun, Mt. Taehwasan, 3 Sep. 2012, B. U. Oh, 120903-256 (KH) \\
\hline & Korea, Gyeongsangbuk-do, Chilgok-gun, Mt. Sandubong, 19 Sep. 1998, B. U. Oh et al., 770 (KH) \\
\hline & Korea, Gyeongsnagnam-do, Hapcheon-gun, Mt. Gayasan, 15 Aug. 1983, I. M. Kim \& S. K. Kim (KH) \\
\hline & Korea, Hamgyeongnam-do, Sinheung-gun, Handaeri, 15 Aug. 1935, T. Nakai, 15787 (TI) \\
\hline & Korea, Jeollabuk-do, Muju-gun, Mt. Deokyusan, 15 Sep. 2002, H. T. Im, 020854 (CNU) \\
\hline
\end{tabular}

점, 타이완 4점), 해변취 6점(제주), 각시취 6점(한반도) (Table 2). 해변취의 집단내 변이 폭을 인식하기 위해 제주
도 제주시의 용두암, 도두봉, 별도봉에 있는 자생 집단에

서 표본 채집과 생태조사를 하였다. 일본산 큰각시취와 
의 비교를 위해 주분포지인 규슈(Kyushu, 九州)의 나가사 키현(Nagasaki-ken, 長崎県), 사시다케(Sasi-dake, 佐志岳) 에서 표본 채집과 생태 조사를 했다. 확보된 석엽표본을 이 용하여 취나물속의 주요 형태형질인 엽형, 화서형, 총포의 크기, 총포편의 형태, 소화, 수과 및 관모 등의 형태적 분석 을 했다. 양적형질의 측정에는 digital caliper를 사용했다.

\section{결과 및 고찰}

\section{큰각시취, 해변취, 각시취의 형태적 차이}

큰각시취, 해변취, 각시취 분류군의 형태적 다름을 확 인하기 위해 취나물속의 주요 형태형질인 엽형, 화서형, 총포의 크기, 총포편의 형태, 소화, 수과 및 관모를 비교 하였다(Table 3). 이들 세 분류군은 총포편 끝에 건막질 (appendage)의 분홍색 부속체가 발달하는 이년초로 깃분 취아절(sect. Theodorea)에 속한다. 이들은 상호 유연관계 가 높은 분류군들로 우상으로 갈라지는 타원형 또는 장 타원형의 잎과 많은 꽃이 밀집된 산방화서를 가지고 있 어서 외부 형태가 매우 유사하다. 소화, 수과 및 관모의 길이에 있어서는 다소의 차이가 있으나, 변이 폭이 넓게 겹쳐 있어서 이들 분류군의 식별에 유용하지 않았다. 개 화하기 전의 외부형태에 있어서 세 분류군은 매우 유사 하여 서로 구별할 수 없지만, 개화기에 도달한 각시취는 총포 및 총포편의 특징에 있어서 큰각시취 및 해변취와 쉽게 구별된다. 총포의 길이와 폭은 연속된 양적형질로 서 각시취의 작은 개체는 큰각시취미 해변취의 큰 개체 와 비슷할 수 있으나, 이들 두 형질의 조합인 총포의 모양 은 서로 다르다. 총포의 모양에 있어서 큰각시취(8$11.5 \mathrm{~mm} \times 5.5-8.2 \mathrm{~mm})$ 와 해변취 $(7.8-10.4 \mathrm{~mm} \times 5.5-$
$8.1 \mathrm{~mm})$ 는 통형이고, 각시취는 종형 $(9.8-15 \mathrm{~mm} \times 8.8-$ $12.5 \mathrm{~mm}$ )이다(Fig. 1).

또한 큰각시취와 해변취는 총포편의 부속체가 직립하 지만, 각시취는 총포편의 부속체가 젖혀진다(Fig. 2). 이 에 비해 큰각시취와 해변취는 조사한 형태형질에 있어서 서로 구별되지 않아서 동일한 분류군으로 인식하는 것이 타당하다.

\section{큰각시취와 각시취의 분포}

주요 표본관 소장 표본 $(\mathrm{KB}, \mathrm{KH}, \mathrm{CNU})$ 중 큰각시취로

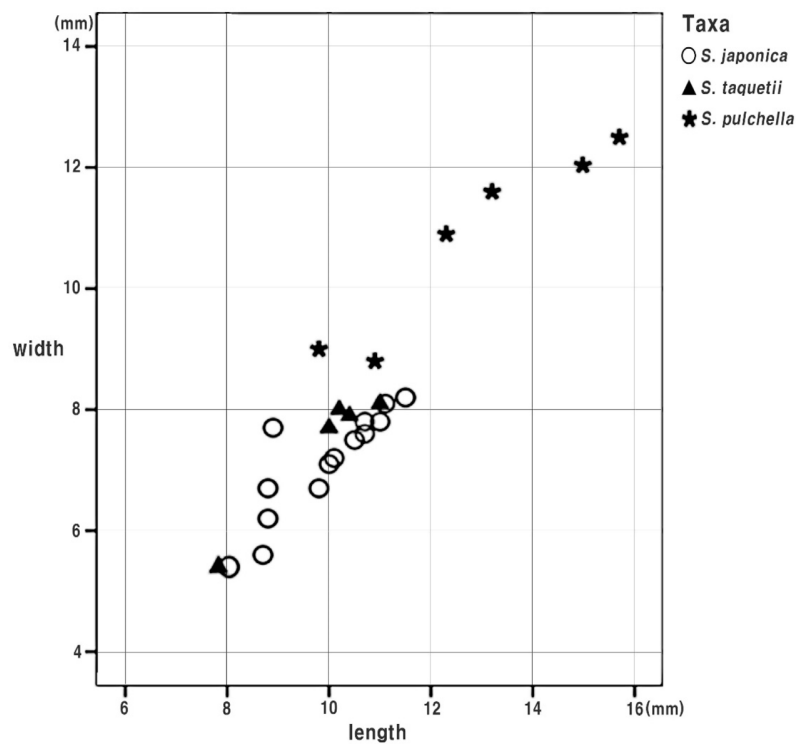

Fig. 1. Scatter plot of involucre (length, width) between Saussurea iaponica (open circle), S. taquetii (triangle) and S. pulchella (star).

Table 3. Major morphological characters and flowering period of Saussurea japonica, S. taquetii and S. pulchella.

\begin{tabular}{lccc}
\hline \multicolumn{1}{c}{ Characters } & S. japonica & S. taquetii & S. pulchella \\
\hline Leaves & Pinnately cleft & Pinnately cleft & Pinnately cleft \\
Division & Elliptical, oblong & Elliptical, oblong & Elliptical, oblong \\
Shape & Dense corymb & Dense corymb & Dense corymb \\
Inflorescence type & & & Campanulate \\
Involucre & Tubular & Tubular & $9.8-15$ \\
Shape & $8-11.5$ & $7.8-10.4$ & $8.8-12.5$ \\
Length (mm) & $5.5-8.2$ & $5.5-8.1$ & Recurved \\
Width (mm) & & & $9-14$ \\
Phyllaries & Erect & Erect & $3-5.5$ \\
Apical appendage & $10-14$ & $12-14$ & $7-10$ \\
Florets length (mm) & $3-4$ & $2.5-4$ & Aug.-Oct. \\
Achene length $(\mathrm{mm})$ & $6-8$ & $5-9$ & Jul.-Aug. \\
Pappus length $(\mathrm{mm})$ & Aug.-Nov. & & \\
Flowering period & & & \\
\hline
\end{tabular}




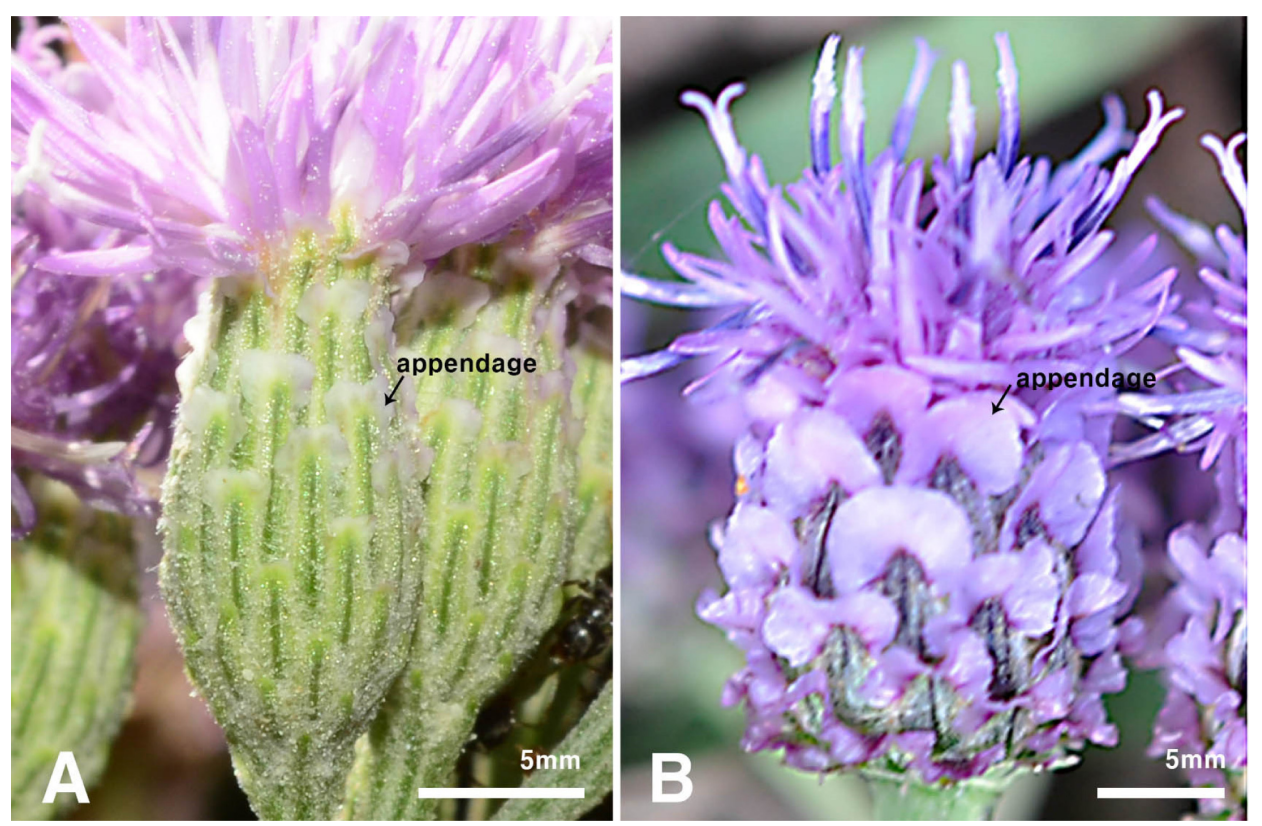

Fig. 2. Species diagnostic differences between Saussurea taquetii and S. pulchella. A. S. taquetii (Yongdu-am, Jeju), involucre width 5-9 mm, scarious apical appendage erect. B. S. pulchella (Mt. Hambaeksan, Gangwon-do), involucre width 9-15 mm, scarious apical appendage recurved.

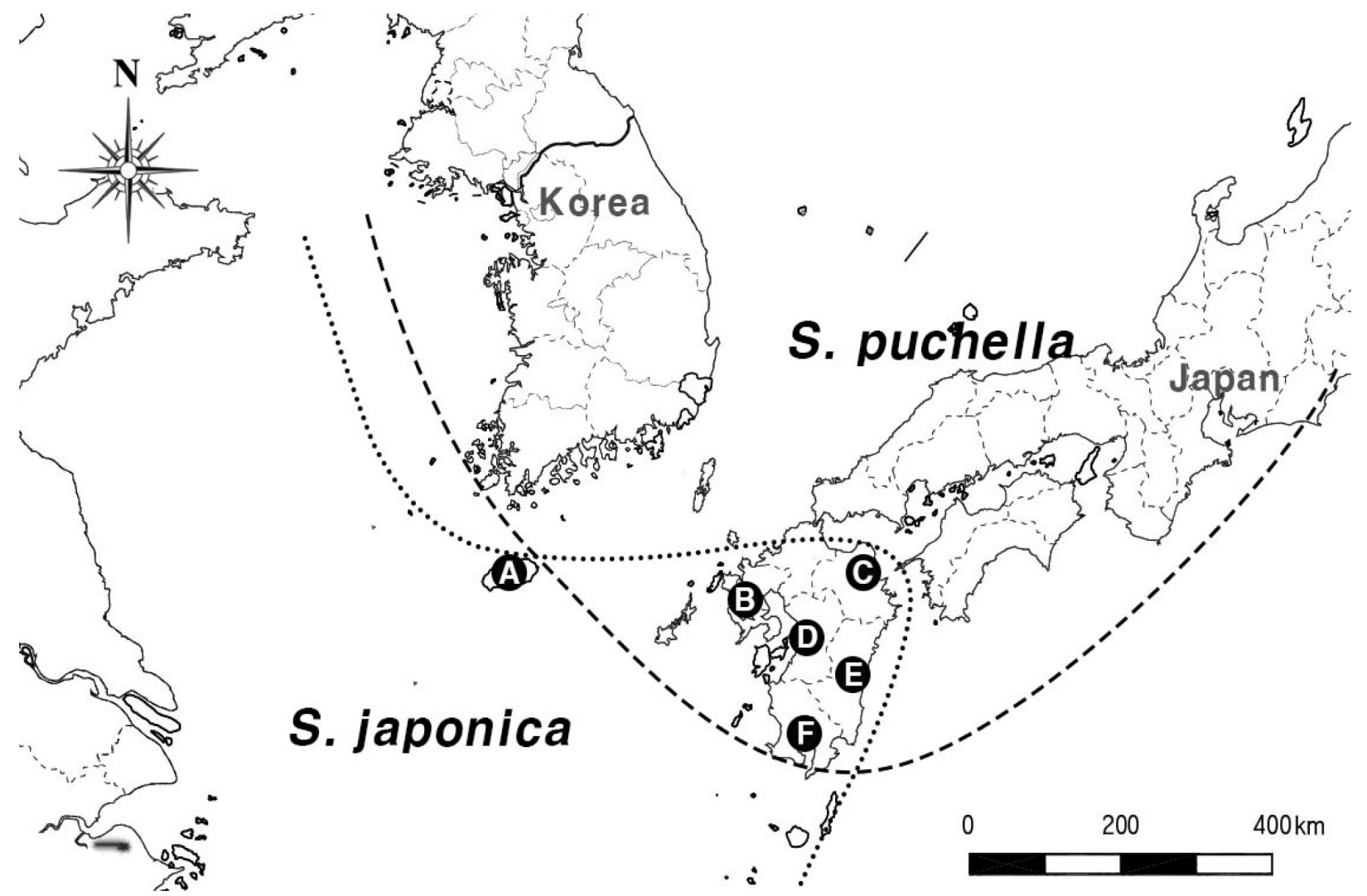

Fig. 3. Distribution of Saussrea japonica/taquetii and S. pulchella in Korea and Japan. Saussurea japonica/taquetii are restricted to Jeju Island (A) and Kyushu (B, Nagasaki; C, Oita; D, Kumamoto; E, Miazaki; F, Kagoshima), while S. pulchella occurs widely in the Korean Peninsula and the Japanese archipelago. 
동정된 표본 중 상당수가 각시취의 오동정이었다. 각시 취와 큰각시취는 개화기에 도달하여 총포와 총포편 부속 체가 충분히 발달하면 쉽게 구별할 수 있지만, 개화기에 도달하기 전의 개체를 엽형과 화서 형태만으로 구별할 수는 없다. 또한 주요 식물도감(Lee, 1998; Lee, 2003)을 포 함한 기존의 문헌(Lipschitz, 1979; Koyama, 1995; Im, 1999; Shi and Raab-Straube, 2011; Kadota, 2017)은 각시취 와 큰각시취 모두 한반도 전역에 분포하는 식물로 기재 하고 있다. 이러한 이유로 각시취의 어린 개체 또는 작은 개체를 큰각시취로 오동정해 온 것으로 추정된다. 주요 표본관에서 확인한 표본 중 제주를 제외한 한반도에서 채집된 표본은 모두 각시취로서, 적어도 한반도 중부 이 남에는 큰각시취가 분포하지 않는 것으로 추정된다. 이 에 반해서 제주도산 표본은 모두 큰각시취로 확인되었으 며, 이들은 특히 제주 북서해안에 국한되어 분포하고 있 다. 결과적으로 우리나라의 경우 각시취는 제주도를 제 외한 한반도 본토에 넓게 분포하고, 큰각시취는 제주도 북서해안에만 분포하는 희귀식물로 확인되었다(Fig. 3). “제주도의 해변취는 본토의 큰각시취와 다르다"는 견해 는 큰각시취의 실체를 명확히 모르는 상황에서 본토의 각시취 중 일부를 큰각시취로 오동정했기 때문으로 생각 된다.

\section{제주도의 큰각시취와 일본의 큰각시취}

제주도의 큰가시취는 제주도의 제주공항을 중심으로 북서부 해안지대에 국한되어 자란다. 용두암 집단은 해 안 암벽사면 사이에 발달한 초지에 자라고 있고, 도두봉 과 별도봉의 집단은 산록 하부 해안 초지에 자라고 있다. 큰각시취의 생육지는 교목이 없고 광환경이 좋은 지역으 로 실고사리, 산박하, 예덕나무, 담쟁이덩굴, 댕댕이덩굴, 갯기름나물, 잔대, 쇠채, 개쑥부쟁이, 쇠고비, 털머위, 왕 모시풀, 덩굴민백미꽃, 갯무, 대나물, 단풍마, 질경이, 개 밀, 개망초, 장구밥나무, 쑥, 큰방가지똥, 명아주, 좀뀡의 다리, 용가시나무, 쇠무릎, 호장근, 거지덩굴, 환삼덩굴, 갯까치수염, 노박덩굴, 고사리, 층꽃나무, 으아리, 참싸리, 자귀나무, 등골나물, 새, 큰기름새, 솔새 등 사면 하부 및 해안 초지의 식물들이 높은 밀도로 생육하고 있다.

일본의 경우 각시취는 홋카이도에서 규슈에 걸쳐 넓게 분포하지만, 큰각시취는 규슈 지역에 국한되어 자란다(Fig. 3). 두 종 모두 일본 환경청의 red data (Yahara, 2003)에 올라 있는 식물로, 큰각시취(endangered [EN] 등급)가 각시취 (vulnerable [VU] 등급)보다 희귀한 식물이다. 일본 규슈 나 가사키현 사시다케(Nagasaki-ken Hirato-si Mukaehimosasi-cho (迎紐差志町), Sasi-dake (佐志岳; $33^{\circ} 13.555 \mathrm{~N}, 129^{\circ} 24.692 \mathrm{E}$ )에 있는 큰각시취 자생지는 산지 사면의 인공 초원지대로서 역사적으로 마을 공동체의 풀 채취 장소로 이용되어 왔 으며, 현재는 그 전통을 계승하기 위해 매년 불을 놓아서 천이가 진행되지 않도록 관리하고 있다. 큰각시취는 사
시다케의 개활된 인공 초지에서 작은 집단을 이루어 자 라고 있으며, 이 집단의 생육환경은 제주도 해변취와 매 우 유사하다. 한반도에서 유래한 대표적 식물인 구절초 (일본에서는 매우 희귀하여 EN종으로 보호하고 있음)를 비롯하여 고사리, 실고사리, 풀고사리, 발풀고사리, 양지 꽃, 자귀나무, 좀싸리, 개싸리, 참싸리, 멀꿀, 좀꿩의다리, 백리향, 산박하, 광나무, 예덕나무, 으아리, 모람, 모새나 무, 동백나무겨우살이, 까마귀쪽나무, 산국, 털머위, 만두 나무속(Glochidion sp.), 산닥나무, 댕강나무속(Abelia sp.), 층꽃나무, 절국대, 민백미꽃, 산해박, 뚝갈, 쑥, 등골나물, 개쑥부쟁이, 닭의난초, 제비난초속(Platanthera sp.), 실부 추, 솔새, 큰기름새, 새, 억새, 쓴풀, 자주쓴풀 등이 자라고 있으며, 전체적으로 한라산 산록 임연부 또는 해안가 초 지와 유사한 식물상 및 경관을 보인다.

제주도의 큰각시취와 일본의 큰각시취는 개화시기가 서로 다르다. 제주도산 큰각시취는 7 월 중순에서 8 월에 걸쳐 개화하여 9 월 중순이면 대부분의 꽃이 시들어 버리 지만, 일본산 큰각시취의 개화시기는 9월에서 11 월로 기 재되어 있다(Koyama, 1995; Kadota, 2017). 동경대학 표본 관(TI)의 큰각시취 석엽표본도 모두 10 월-11월 사이에 채 집되었으며, 가을에 이루어진 본 연구의 나가사키 조사 (2019년 9월 9일-10일)에서 확인된 개체들 역시 모두 이 제 막 추대(bolting)가 시작된 어린 꽃망울 상태였다.

\section{해변취의 분류학적 실체}

본 연구에서 제주도의 해변취는 큰각시취와 형태적, 생태적으로 동일한 분류군임이 확인되었다. 제주도의 큰 각시취가 한여름인 7-8월에 대부분 개화하는 것에 비해 일본의 큰각시취는 보다 늦게 8-11월에 개화하는 다름이 있다(Table 3). 그러나 보다 따뜻한 지역인 타이완의 큰각 시취 중에는 12 월 개화한 개체도 있어서 제주도산 큰각 시취의 이른 개화는 상대적으로 겨울이 빨리 오는 제주 도의 환경 특성에 의한 것으로 추정된다. 해변취는 큰각 시취의 이명이며, 우리나라의 큰각시취는 제주도에만 자 라는 것으로 확인되었다(Fig. 4). 큰각시취가 포함되는 한 반도산 sect. Theodorea의 검색표를 아래에 제시하였다. 중국식물지에는 큰각시취 중 엽병에 발달한 날개가 줄기 에 연결되는 식물을 변종으로 인식하여 Saussurea japonica var. pteroclada (Nakai \& Kitagawa) Raab-Straube 로 부르고 있다(Stem conspicuously winged; wings entire or dentate. Leaf blade base decurrent) (Shi and Raab-Straube, 2011). 이는 일본의 Nakai와 Kitagawa가 중국 동북지방(만 주) 식물조사에서 언급한 Saussurea microcephala var. pteroclada Nakai \& Kitagawa (Kitagawa, 1934)에 기초하고 있다. 해당 식물을 직접 보지 못하였고, 정확한 기재도 없 는 상태이므로 그 분류학적 타당성을 따질 수는 없으나, “엽병에 발달한 날개가 줄기에 연결되는 특징”은 각시취 나 당분취(S. tanakae Fr. \& Sav.)에서도 볼 수 있는 연속변 

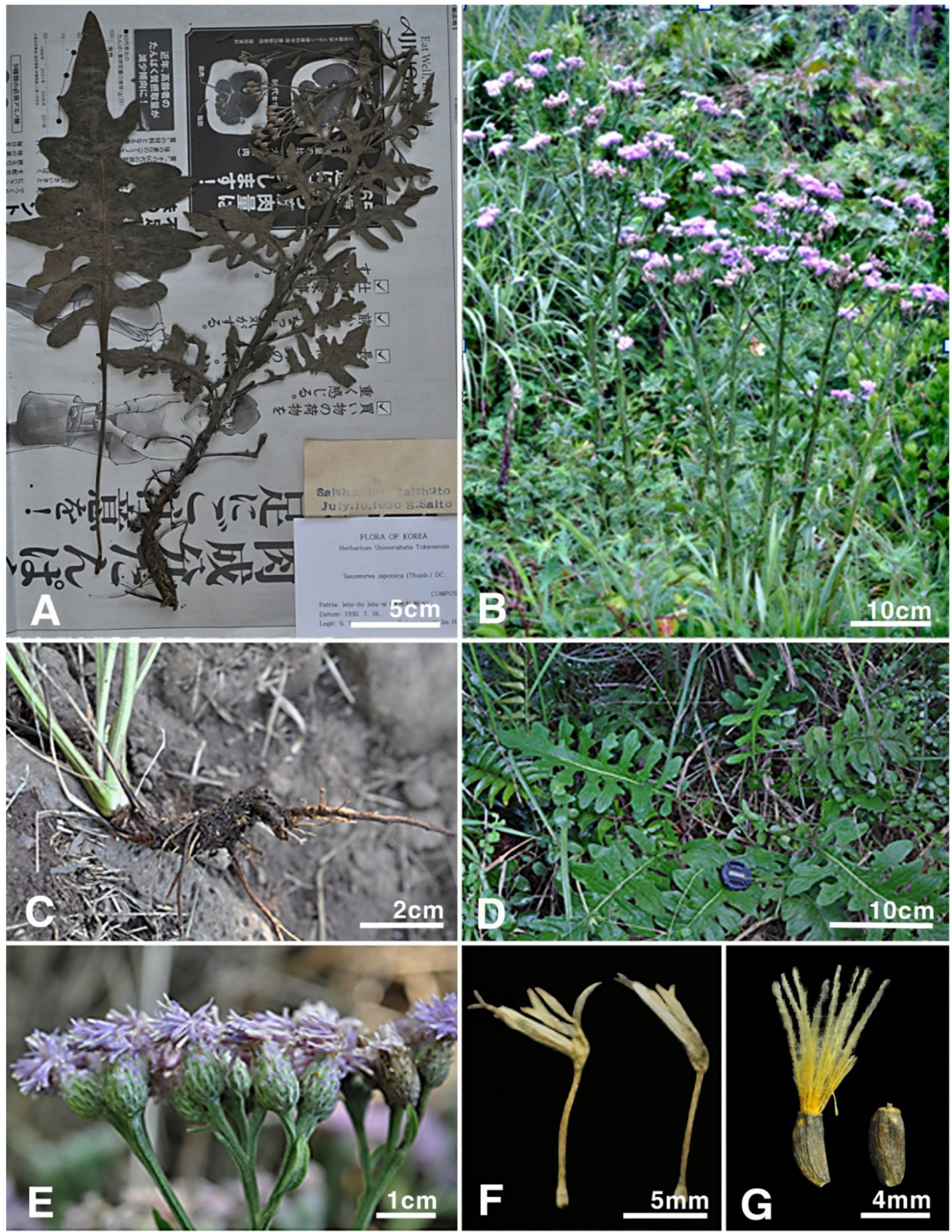

Fig. 4. Photographs of Saussurea japonica in Korea. A. Historical specimen collected in Jeju, 10 Jul 1930. B. Habit. C. Root. D. Radical leaves. E. Inflorescence. F. Floret. G. Achene. 
이로서 변이 폭이 크다. 제주도의 큰각시취 역시 동일 집 단 내에 날개의 발달 정도가 서로 달라서 개체에 따라 날 개의 폭이 1-6 mm에 이르며, 일본의 큰각시취 역시 "winged or not"으로 기재되어 있다(Koyama, 1995).

\section{분류군의 기재}

Saussurea japonica (Thunb.) DC., Ann. Mus. Natl. Hist. Nat. 16: 203, 1810; Serratula japonica Thunb. in Murray, Syst. Veg., ed. 14: 723, 1784.-TYPE: JAPAN. Thunberg s.n. (BM, photo!).

Saussurea taquetii H. Lév. \& Vaniot, Repert. Spec. Nov. Regni Veg. 8: 169, 1910.-TYPE: KOREA. "Quelpart, in herbidis litoris Tchyoung-Tchyeng-Koan," Sep 10, 1908, Taquet 1015 (E, photo!).

Saussurea taquetii var. paniculata H. Lév. \& Vaniot, Repert. Spec. Nov. Regni Veg. 8: 169, 1910.-TYPE: KOREA. "Quelpart, in herbidis Sampangsan," Oct 1908, Taquet 1016 (E, photo!).

Plants biennial, $0.5-1.4 \mathrm{~m}$ tall. Roots taproot. Stems erect, branched, striate, winged or not, sparsely pubescent with glandular hairs. Leaves alternate; basal leaves persistent at anthesis; petiole 3-6 cm long; blade oblong, usually pinnately parted, $20-35 \times 8-13 \mathrm{~cm}$ long, apex obtuse, terminal lobe narrowly lanceolate, lateral lobes 7 or 8 pairs, narrowly oblong, usually pinnately lobulate; median cauline leaves gradually smaller upward; petiole $0.5-1 \mathrm{~cm}$ long; blade elliptic to lanceolate, pinnately cleft; upper cauline leaves sessile; blade linear-lanceolate; both surfaces glandular hairy. Heads 40-80, in dense corymbiform synflorescence; peduncle slender, $0.5-$ $2 \mathrm{~cm}$ long; involucre narrowly campanulate or tubular, 0.8 $11.5 \mathrm{~cm} \times 5-8.2 \mathrm{~mm}$; phyllaries 6-seriate, with a pale purplish scarious appendage apically, cobwebby; outer phyllaries ovate, apex obtuse, ca. $2.5 \mathrm{~mm}$ long; middle phyllaries narrowly oblong; inner phyllaries linear, $0.8-1.3 \mathrm{~cm}$ long. Florets purple; corolla 1-1.4 cm long. Cypselae ellipsoid, slightly tetragonal, 3.5-4 mm long, glabrous; pappus, outer series white, capillary, ca. $2 \mathrm{~mm}$ long; inner series grayish white, 6-8 $\mathrm{mm}$ long.

Flowering: Aug. to Oct.

Habitat: Grassland on lowland adjacent to coast.

Distribution: China, Japan (Kyushu), Korea (Jeju-do), Mongolia, Taiwan.

1. 엽신은 좁은 피침형으로 가장자리가 밋밋하다 남포분취 S. chinnampoensis

1. 엽신은 타원형 또는 긴 타원형으로 가장자리가 갈 라진다.
2. 총포는 종형으로 총포편의 부속체는 반곡한다 …... 각시취 S. pulchella

2. 총포는 통형으로 총포편의 부속체는 직립한다 …… 큰각시취 S. japonica

ORCID: Eun-Mi SUN https://orcid.org/0000-0001-76918094; Seon A YUN https://orcid.org/0000-0002-4961-7189; Seung-Chul KIM https://orcid.org/0000-0003-0559-6782; Hyoung-Tak IM http://orcid.org/0000-0002-6333-6244

\section{Acknowledgments}

This work was supported by a grant from the National Institute of Biological Resources (NIBR), funded by the Ministry of Environment (MOE) of the Republic of Korea (NIBR202107101).

\section{Conflicts of Interest}

The authors declare that there are no conflicts of interest.

\section{Literature Cited}

Im, R. J. 1999. Saussurea. In Flora Coreana, Vol. 7. The Science and Technology Publishing House, Pyongyang, Pp. 93-116. (in Korean)

Kadota, H. 2017. Genus Saussurea DC. In Wild Flowers in Japan. Vol. 5. Ohashi, H. (ed.), Heibonsha Ltd, Tokyo. Pp. 255-272. (in Japanese)

Kitagawa, M. 1934. Report of the First Scientific Expedition to Manchoukuo, IV 1: 62.

Kitamura, S. 1937. Compositae japonicae. Pars Prima. Memoirs of the College of Science, Kyoto Imperial University, Series B 13: $140-212$

Korea National Arboretum. 2016. Distribution Maps of Vascular Plants in Korea. Korea National Arboretum, Pocheon, 828 pp.

Koyama, H. 1995. Saussurea. In Flora of Japan IIIb. Iwatsuki, K., T. Yamazaki, D. E. Boufford and H. Ohba (eds.), Kodansha Ltd., Tokyo. Pp. 152-162.

Lee, T. B. 2003. Coloured Flora of Korea. Vol. 1. Hyangmunsa Publishing Co., Seoul, 901 pp. (in Korean)

Lee, W. T. 1996. Coloured Standard Illustrations of Korean Plants. Academy Publishing Co., Seoul, 1,688 pp.

Lee, Y. N. 1998. Saussurea. In New Flora of Korea. Kyohak Publishing Co., Ltd., Seoul, 1,247 pp. (in Korean)

Léveillé, H. 1910. Decades plantarum novarum. XXXI-XXXII. Repertorium Specierum Novarum Regni Vegetabilis 8: 168172. 
Lipschitz, S. 1979. Genus Saussurea DC. (Asteraceae). Nauka, Leningrad. Pp. 180-207. (in Japanese)

Shi, Z. \& E. von Raab-Straube. 2011. Saussurea Candolle. In Flora of China. Vol. 20-21 (Asteraceae). Wu, Z. Y., P. H.
Raven and D. Y. Hong (eds.), Science Press, Beijing and Missouri Botanical Garden Press, St. Louis, MO. Pp. 56-149.

Yahara, T. 2003. Red Data Plants. Yama-Kei Publisher Co., Ltd., Tokyo. 719 pp. (in Japanese)

\title{
해변취의 실체: 큰각시취/각시취|와의 관계 \\ 선은미 · 윤선아 ${ }^{1} \cdot$ 김승철 $\cdot$ 임형탁 ${ }^{2}$ \\ 국립백두대간수목원, ${ }^{1}$ 성균관대학교 생명과학과, ${ }^{2}$ 전남대학교 생물학과
}

\begin{abstract}
적 요: 제주도에서 보고된 해변취는 일반적으로 큰각시취의 이명으로 인식되고 있으나, 한반도의 큰각시취 와는 다른 식물이라는 견해가 상존한다. 큰각시취는 총포편의 선단에 옅은 보라색의 건막질 부속체가 있는 이년생 초본으로 취나물속의 깃분취아절(sect. Theodorea)에 속하며, 형태적으로 유사한 분류군인 각시취와 함께 우리나라 전역에 분포하는 것으로 알려져 있다. 해변취의 실체를 확인하기 위해 제주도의 해변취 자생 지와 일본 규슈의 큰각시취 자생지에서 채집 및 조사를 하였다. 형태적 유연관계를 확인하기 위해 본 연구에 서 채집된 표본과 국립수목원(KH), 전남대학교 표본실 $(\mathrm{CNU})$, 토쿄대학 표본실(TI) 소장 큰각시취 및 각시취 표본을 비교 분석하였다. 해변취는 일본 규슈의 큰각시취와 형태적 및 생태적으로 구별되지 않아서 큰각시 취의 이명으로 처리하였다. 식물종의 분포에 있어서 기존 견해와 달리 한반도에는 각시취만 분포하며, 제주 도에는 큰각시취만 분포한다.
\end{abstract}

주요어: 해변취, 큰각시취, 각시취 